\title{
THE FIRST HAEMOLYMPH ANALYSIS OF NHANDU CHROMATUS TARANTULAS - BIOCHEMICAL PARAMETERS
}

\author{
Muir, R. E., Halán, M. \\ Department of Parasitology, University of Veterinary Medicine and Pharmacy \\ Komenskeho 73, 04181 Košice \\ The Slovak Republic
}

milos.halan@uvlf.sk

\section{ABSTRACT}

Tarantulas are a relatively unstudied category of invertebrate which are popular with hobbyists and increasingly used in laboratory research. As their presence in the veterinary setting is limited, very little is known about the biochemistry of their haemolymph as obtained by in house sampling and analysis. A handful of studies have been performed to attempt to establish a normal range for certain parameters in healthy members of a few particular species, but that is the extent of the current research. In this study, 12 tarantulas of the Nhandu chromatus species purchased as immature siblings and kept under standardised conditions for 2.5 years were anaesthetised with isoflurane and had $0.2 \mathrm{ml}$ of haemolymph sampled and analysed for: total protein, glucose, calcium, phosphorous and uric acid. As well as having kept a diary of their daily feed intake and recorded dates of ecdysis, the exposure time to anaesthetic and perceived effectiveness were recorded. The variables originally proposed for this investigation are based on 2 separate feeding regimes, differing in terms of feed quantity and the effect on the aforementioned biochemical parameters. Upon receipt of the biochemical results from the first sampling, it became apparent that unexpected correlations could be made between the stage of ecdysis, susceptibility to anaesthesia and the total protein levels in the haemolymph. Those that were due to shed imminently, indicated by cessation in feeding, had recognisably and significantly higher total protein levels and reached a better level of anaesthesia in less time. Additional samplings are planned in the future to specify more definitive parameters. The observations made inadvertently so far could constitute novel information and be practically useful to tarantula enthusiasts and anaesthetists, and therefore, potentially of high clinical significance.

Key words: biochemistry; ecdysis; haemolymph; Nhandu chromatus; tarantula 


\section{INTRODUCTION}

Little is known about the history of keeping tarantulas recreationally but the hobby anecdotally took off in the 1970s with the exportation of Brachypelma smithi and by the 1990s over 200 species were being bred in captivity [3]. They are currently one of the most popular non- mammalian pets, as well as being used in zoological exhibitions and as research specimens [8].

The tarantula species used in this study were Nhandu chromatus commonly known as the "Red and White Brazilian Bird-eater"; so named due to their relatively large size, despite probably not eating birds as part of their diet. In reality, little has been done in the way of nutritional studies of tarantulas in captivity or in the wild [8]. This species is popular in collections due to its large size and striking colouration of a red opistosoma, white prosoma and black and white striped appendages despite their highly defensive reputation [5].

The nutrients and hydration required by arachnids are usually derived from invertebrate prey species that come within reach. Once captured and immobilised, the spider will regurgitate digestive juices onto their prey and digestion begins externally.

The metabolic rate of spiders is extremely low with oxygen consumption being only 100th of that of warm blooded mammals [7]. Starvation has little effect on survival for months on end in order to enable overwintering and periods of reduced feed availability [2].

Due to the lack of a separation between the lymphatic and blood circulatory systems, the circulating fluid which carries oxygenated pigments is called haemolymph. The pigment equivalent to haemoglobin in invertebrates is copper based haemocyanin which is a clear coloured liquid that turns blue and coagulates quickly in contact with air and flows freely in the haemolymph as proteinaceous crystals [8].

Arachnids have a tubular heart which runs dorsomedially within a pericardial sinus along the anterior two-thirds of the opistosoma just ventral to the abdominal exoskeleton [11]. Haemolymph then re-enters the closed circulatory system but the venous return to the heart is via an open circulatory system free flowing amongst the tissues [4].

Within the bodies of all arachnids, a complex of prosomal and opisthosomal muscles can generate locally increased haemolymph pressure within the semi-open circu- latory system. This is the mechanism by which all locomotive and tactile movements occur and can be referred to as a hydraulic system [6].

As far as we know, only 1 study has been performed analysing the biochemical parameters of tarantula haemolymph using a biochemistry machine such as those that are available to veterinarians. Eleven Theraphosa blondi and twelve Grammostola rosea tarantulas were sampled by Zach ariah et al. in 2007 [12] immediately after wild capture and 8 weeks later after a period of good nutrition and hydration. Significant differences in body weight, sodium, potassium, and osmolality between the sampling times for both species were seen. There were also significant differences in: creatine kinase, calcium, total protein, and blood urea nitrogen between the sampling periods for T.blondi. The results of that study suggested that serial haemolymph samples may be used to assess the hydration status of theraphosid spiders. Differences seen in the biochemical results for different species in the aforementioned study, as well as those obtained by Stewart and Martin in 1970 [9] for Dugesiella hentzi, show the importance of defining the normal levels for each species.

The aim of this study was to determine the physiological values of selected biochemical parameters in the haemolymph of tarantulas Nhandu chromatus and obtain relevant information regarding their stage of ecdysis and anaesthesia susceptibility.

\section{MATERIALS AND METHODS}

The test subjects used in this study $(n=12)$ were purchased as immature siblings from a private breeder and subsequently kept under identical conditions for 2.5 years. They were individually housed in a quiet room with a steady temperature of $24^{\circ} \mathrm{C}$ in $26 \times 19 \times 14 \mathrm{~cm}$ clear plastic boxes with perforated lids, each with a halved large yoghurt pot for shelter on a peat based substrate with high acidity to prevent fungal and parasite growth. Each box was labelled with their personal number from 1 to 12 to aid with record keeping. A small bottle top filled with water every 2-3 days was provided for ad libitum drinking, as well as additional watering of the soil to maintain a reasonable humidity when it became dry.

The vivariums were only disturbed every $2-3$ days for feeding, watering and removal of mould or shed skins. Re- 
cords were kept detailing the number of cockroaches fed, individuals that had shed and individuals that had not eaten since the last feeding, as well as ambient temperature and any additional notes every time they were visited.

Each individual was fed every 2 to 3 days with either 4 live, similar sized Blatta orientalis cockroaches or Brown crickets Acheta domesticus.

Anaesthesia was performed in their vivariums, with the lid from their enclosure exchanged for a non-perforated lid with a hole cut out for airtight application of the anaesthesia circuit. Each spider was anaesthetised with $5 \%$ isoflurane (Furane, Baxter Healthcare Corporation, Deerfield, IL 60015 , USA) at a flow rate of $21 \cdot \mathrm{min}^{-1}$ for $5-15$ minutes, depending on the effect [1].

Once removed from their vivarium, each tarantula was placed on the table and restrained with a piece of cling film held over their whole body.

An insulin syringe (BD Micro-Fine $\mathrm{e}^{\mathrm{TN}}$ Plus $1 \mathrm{ml}$, Becton, Dickinson and Company, 1 Becton Drive, Franklin Lakes, New Jersey, 07417-1880 201.847.6800) was used by inserting the needle through the cling film at $45^{\circ}$ angle into the dorsal midline at the centre of the opistosoma until haemolymph could be withdrawn directly from the cardiac chamber. $0.2 \mathrm{ml}$ was collected from each tarantula consecutively and transferred to Eppendorf tubes labelled with their personal number.

The cling film was then folded off the opistosoma to allow for the application of $\mathrm{Pasco}^{\oplus}$ super-glue sufficient to seal the injection site to prevent or stop bleeding.

Each individual was transferred to a bowl to be weighed and then returned to their enclosures.

The samples were then centrifuged for 5 minutes at $3.5 \mathrm{rpm}$, then a minimum of $0.1 \mathrm{ml}$ was transferred to the Cobas C111 biochemical analyser (Roche Diagnostics Limited, Forrenstrasse, CH-6343, Rotkreuz, Switzerland).

The Student t-test was the test used to define statistical significance between the imminently shedding and recently shed variables for total protein, glucose and uric acid. The level of significance was set at $\mathrm{P}<0.05$.

\section{RESULTS AND DISCUSSION}

Every tarantula was successfully sampled and yielded biochemical data (Table 1). Results of statistical analysis for each parameter in all 12 tarantulas are presented in Table 2.
The weights of tarantulas were between $6 \mathrm{~g}$ and $10 \mathrm{~g}$, the variety of which was to be expected as some had shed one more time than others. It was also apparent that those weighing $6 \mathrm{~g}$ and $7 \mathrm{~g}$ had shed recently which again was to be expected as they lose the weight of their previous exoskeletons and appear to have smaller abdomens after shedding.

In addition to the biochemical results, the anaesthesia times were recorded with a loose assessment of anaesthetic depth in order to obtain a better standard time for exposure to isoflurane for future samplings. During the course of the sample collection it swiftly became possible to predict each individual's response to anaesthesia by the assessment of their stage of ecdysis (Table 1). This was achieved by visual inspection of each animal and by checking their feeding and shedding records. Those that were approaching shedding had rounder abdomens with hairless patches through which new hairs could be seen growing underneath and all had stopped eating. Throughout the rearing of these test subjects, they had ceased eating for between 0 and 19 days before shedding and the time between sheds ranged from 42 to 113 days. Those that had recently shed had done so within 14 days of the sampling and one shed just 2 days before.

It was observed during the course of the anaesthesias that those fast approaching ecdysis responded to anaesthesia more swiftly and successfully than those that had recently shed, one of whom showed minimal response after 15 minutes of exposure and proved very difficult to restrain.

Upon receipt of the biochemical data, it also became visually apparent that there may be some correlation between the stage of shedding and levels of total protein, glucose and uric acid.

As is demonstrated in Table 3, only total protein showed a high statistical significance between the variables with a $\mathrm{P}$ value of 0.0023 . It is interesting that in a majority of cases, glucose was higher in those which had not eaten for 2 weeks compared to those that had eaten 4 cockroaches within the previous 2 days.

In terms of obtaining a normal range for the species, all of the parameters seem to be without anomalies except for uric acid which shows great variations. This may be due to the temporal proximity of the last defecation, as uric acid is one of the waste products excreted along with guanine, adenine and hypoxanthine [10]. Unfortunately, speculation on the cause of this variety is beyond the scope of this study. 
Table 1. The weight and biochemical results for each tarantula with time and quality of anaesthesia

\begin{tabular}{|c|c|c|c|c|c|c|c|c|c|}
\hline \multirow{2}{*}{$\begin{array}{c}\text { Taran- } \\
\text { tula } \\
\text { ID }\end{array}$} & \multirow{2}{*}{$\begin{array}{l}\text { Weight } \\
{[\mathrm{g}]}\end{array}$} & \multirow{2}{*}{$\begin{array}{c}\text { Total } \\
\text { protein } \\
{\left[\mathrm{g} . \mathrm{I}^{-1}\right]}\end{array}$} & \multirow{2}{*}{$\begin{array}{l}\text { Glucose } \\
{\left[\mathrm{mmol} . \mathrm{I}^{-1}\right]}\end{array}$} & \multirow{2}{*}{$\begin{array}{l}\text { Calcium } \\
{\left[\mathrm{mmol} . \mathrm{I}^{-1}\right]}\end{array}$} & \multirow{2}{*}{$\begin{array}{c}\text { Phosphorus } \\
{\left[\mathrm{mmol}^{\left.-\mathrm{I}^{-1}\right]}\right.}\end{array}$} & \multirow{2}{*}{$\begin{array}{c}\text { Uric acid } \\
{\left[\mathrm{mmol} . \mathrm{I}^{-1}\right]}\end{array}$} & \multirow{2}{*}{$\begin{array}{c}\text { Ecdysis } \\
\text { stage }\end{array}$} & \multicolumn{2}{|c|}{ Anaesthesia } \\
\hline & & & & & & & & $\begin{array}{l}\text { Time } \\
\min \end{array}$ & $\begin{array}{c}\text { Quality } \\
\text { level }\end{array}$ \\
\hline 1 & 9 & 34.2 & 1.02 & 3.03 & 0.18 & 1.5 & Imminent & 5 & Adequate \\
\hline 2 & 7 & 23.2 & 0.62 & 2.89 & 0.27 & 2.5 & Recent & 7 & Adequate \\
\hline 3 & 6 & 26.4 & 0.82 & 3.16 & 0.33 & 0 & Recent & 12 & Poor \\
\hline 4 & 9 & 25.5 & 0.77 & 3.01 & 0.27 & 2.8 & 28 days ago & 10 & Adequate \\
\hline 5 & 8 & 34.1 & 2.4 & 3.3 & 0.22 & 2 & Imminent & 10 & Good \\
\hline 6 & 7 & 22.3 & 0.98 & 2.87 & 0.29 & 0.3 & Recent & 10 & Poor \\
\hline 7 & 10 & 30.3 & 0.88 & 3.28 & 0.31 & 3.8 & Imminent & 8 & Good \\
\hline 8 & 9 & 29.2 & 0.64 & 3.34 & 0.2 & 0 & 33 days ago & 8 & Poor \\
\hline 9 & 9 & 27.9 & 0.96 & 3.46 & 0.24 & 1,6 & Recent & 15 & Poor \\
\hline 10 & 8 & 28.2 & 1.88 & 3.23 & 0.32 & 3 & Imminent & 10 & Good \\
\hline 11 & 9 & 31.1 & 0.92 & 3.55 & 0.26 & 1.2 & Imminent & 8 & Good \\
\hline 12 & 9 & 24 & 1.58 & 3.05 & 0.29 & 0 & Just shed & 12 & Good \\
\hline
\end{tabular}

Table 2. Statistical analysis of all biochemical parameters investigated in 12 tarantulas

\begin{tabular}{|c|c|c|c|c|c|}
\hline Parameter & Mean & Min.-Max. & Range & SD & SEM \\
\hline $\begin{array}{c}\text { Total protein } \\
{\left[\mathrm{g} . \mathrm{I}^{-1}\right]}\end{array}$ & 28.03 & $22.3-34.2$ & 11.9 & 3.9585 & 1.427 \\
\hline $\begin{array}{l}\text { Glucose } \\
{\left[\mathrm{mmol}^{\left.-\mathrm{I}^{-1}\right]}\right.}\end{array}$ & 1.12 & $0.62-2.4$ & 1.78 & 0.5455 & 1.1575 \\
\hline $\begin{array}{l}\text { Calcium } \\
{\left[\mathrm{mmol}^{\left.-\mathrm{I}^{-1}\right]}\right.}\end{array}$ & 3.18 & $2.87-3.55$ & 0.68 & 0.2167 & 0.0626 \\
\hline $\begin{array}{c}\text { Phosphorus } \\
{\left[\mathrm{mmol} . \mathrm{I}^{-1}\right]}\end{array}$ & 0.265 & $0.18-0.33$ & 0.15 & 0.0474 & 0.0137 \\
\hline $\begin{array}{l}\text { Uric acid } \\
{\left[\mathrm{mmol}^{\left.-\mathrm{I}^{-1}\right]}\right.}\end{array}$ & 1.5583 & $0-3.8$ & 3.8 & 1.3049 & 0.3767 \\
\hline
\end{tabular}

SD - standard deviation; SEM — standard error of mean 
Table 3. The results for total protein, glucose and uric acid divided into stages

of ecdysis (excluding the 2 which were in mid-cycle) and the results of the statistical analysis by the Student $t$-test

\begin{tabular}{|c|c|c|c|c|c|c|}
\hline & \multicolumn{2}{|c|}{ Total protein } & \multicolumn{2}{|c|}{ Glucose } & \multicolumn{2}{|c|}{ Uric acid } \\
\hline & Imminent & Recent & Imminent & Recent & Imminent & Recent \\
\hline & 34.2 & 23.2 & 1.02 & 0.62 & 1.5 & 2.5 \\
\hline & 34.1 & 26.4 & 2.4 & 0.82 & 2 & 0 \\
\hline & 30.3 & 22.3 & 0.88 & 0.98 & 3.8 & 0.3 \\
\hline & 28.2 & 27.9 & 1.88 & 0.96 & 3 & 1.6 \\
\hline & 31.1 & 24.0 & 0.92 & 1.58 & 1.2 & 0 \\
\hline $\begin{array}{c}\text { Student } \\
t \text {-test }\end{array}$ & \multicolumn{2}{|c|}{$\begin{array}{l}\text { Two-tailed } \\
P=0.0023^{*}\end{array}$} & \multicolumn{2}{|c|}{$\begin{array}{l}\text { Two-tailed } \\
P=0.2506\end{array}$} & \multicolumn{2}{|c|}{$\begin{array}{l}\text { Two-tailed } \\
\mathrm{P}=0.0759\end{array}$} \\
\hline Mean & 31.58 & 24.78 & 1.42 & 0.992 & 2.3 & 0.88 \\
\hline SD & 2.574 & 2.324 & 0.6844 & 0.3588 & 1.082 & 1.121 \\
\hline SEM & 1.151 & 1.04 & 0.3061 & 0.1604 & 0.484 & 0.501 \\
\hline
\end{tabular}

SD — standard deviation; SEM - standard error of mean; * $-\mathrm{P}<0.05$

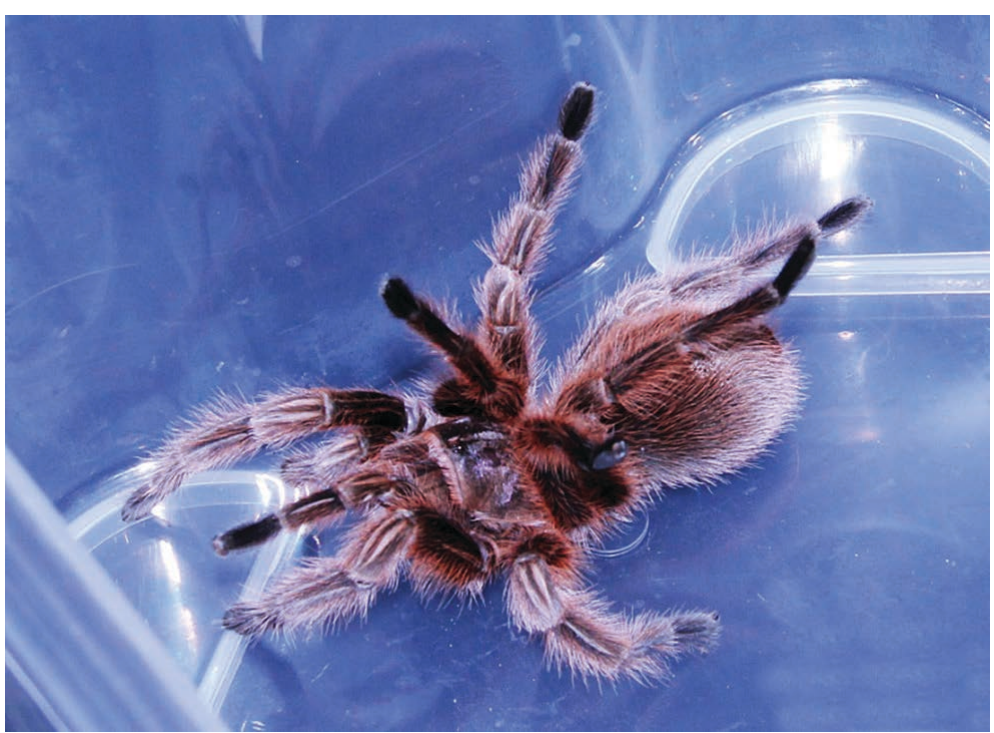

Fig. 1. The dorsal hyper-extension of legs seen during anaesthesia of an adult female Grammostola rosea in a pilot study for this experiment 
All of the test subjects survived sampling with no adverse effects to either the anaesthesia or having $0.2 \mathrm{ml}$ of haemolymph taken. Some individuals proceeded to shed within the next few days and they all resumed eating two days later.

Tarantulas, like other invertebrates have an exoskeleton and, must shed in order to increase in body size and reach maturity. It is well known that shedding occurs more frequently in spiders that are being fed more. "Power feeding" is used by tarantula dealers in order for their animals to reach maturity faster and fetch a higher price in less time.

As of yet there are no reports on the stage of ecdysis effecting susceptibility to anaesthesia to compare with the results gained in this study. Despite the lack of quantitative data retrieved so far, it is possible to visually compare the anaesthesia time and effectiveness in comparison to the stage of shedding.

This study is intended to continue with 3 other samples being taken a month apart to assess the effect of the feeding regimes on haemolymph biochemical parameters with the 12 tarantulas being split into two groups of 6 , one fed 10 times more than the other group, then fed equal amounts the next month, then reversed. In future samplings it will hopefully be possible to accurately record the time taken before full anaesthesia is reached. This would be accomplished by implementing tests such as touching the legs or testing the self righting reflex as performed in a study by Dombrowski et al. in 2013 [1] when comparing isoflurane and carbon dioxide anaesthesia in Grammostola rosea tarantulas.

Another interesting observation made during anaesthesia of certain tarantulas was a strange, momentary, unnatural positioning of the limbs during induction seen in Fig. 1. It only occurred in those which responded more quickly to anaesthesia and appeared to be a hyper-extension of the legs dorsally above the prosoma, then relaxation into a normal position a few seconds later. It is possible that this previously undescribed phenomenon could act as an indicator of anaesthetic depth and will be recorded in more detail during subsequent samplings.

This interesting reflex and the observed correlation between the stage of ecdysis and anaesthesia quality, can surely contribute to the minimal knowledge currently available on tarantula anaesthesiology. Practically it may help veterinarians and researchers to predict the amount of time they should expect for full anaesthesia of tarantulas if they have access to their history. It may even prevent accidents from occurring involving more recently shed individuals who are still able to evade restraint after the same exposure to isoflurane as others.

The statistical significance in the difference between total protein in the haemolymph of tarantulas classified as recently shed and imminently shedding is also novel information. It will have to be supported by future samples and studies but may also help in the identification of the stage of ecdysis in individuals obtained without a history. In future studies, it may be possible to identify a specific level of protein that needs to be reached in the haemolymph by means of feed intake in order for healthy individuals to cease eating as is normal during pre-moult.

\section{CONCLUSIONS}

As so little is known about tarantula haemolymph, especially from Nhandu chromatus, any information gathered, whether to set a standard range for healthy animals or to investigate ill health, is valuable. Tarantulas are greatly under-represented in veterinary clinics, but this may change as our comprehension of their physiology improves.

Similar studies in the future will hopefully provide more and more accurate ranges for biochemical parameters and further investigate the observations made regarding the stage of ecdysis and anaesthesia susceptibility. Hopefully one day it will be possible to sample haemolymph and run biochemical analysis in veterinary clinics in order to diagnose diseases in arthropod patients with a view to treating them. This option is, as of yet, unavailable to us but this study has shown that $0.2 \mathrm{ml}$ can be safely taken from $6 \mathrm{~g}$ tarantulas and at least 5 biochemical parameters can be obtained from this.

\section{ACKNOWLEDGEMENTS}

We wish to thank to the Department of Parasitology for accommodating the tarantulas and to the Exotic Animal Surgery Department for allowing the use of their anaesthesia machine for so many hours. Also many thanks belong to Muhammed Siddiq Patel for helping with feeding and proof reading when we needed a hand. 


\section{REFERENCES}

1. Dombrowski, D.S., De Voe, R.S., Lewbart, G. A., 2013: Comparison of isoflurane and carbon dioxide anaesthesia in Chilean Rose tarantulas (Grammostola rosea). Zoo Biology, 32, $101-103$.

2. Foelix, R.F., 1996: Biology of spiders. Oxford University Press, New York, 432 pp.

3. Gearheart, T., 2011: Beginners Guide to the Tarantula Keeping Hobby, http://tarantulaspiders.com/Tarantulas-Intro. html, Accessed on the 7th of November, 2015.

4. Huckstorf, K., Michalik, P., Ramírez, M., Wirkner, C.S., 2015: Evolutionary morphology of the hemolymph vascular system of basal araneomorph spiders (Araneae: Araneomorphae). Arthropod Structure and Development, 44, 609-621.

5. Jacobi, M.A., 2007: Brazilian Red and White Tarantula Concise and Precise Care Sheet, http://ExoticFauna.com.. Accessed on the 7th of November 2015.

6. Kropf, C., 2013: Chapter 4: Hydraulic system of locomotion. Spider Ecophysiology, Springer-Verlag, Berlin, 43-56.

7. Paul, R. J., 1990: La respiration des arachnides. Recherche, 226, 1338-1357.

8. Pizzi, R., 2006: Chapter 10: Spiders. Invertebrate Medicine, Blackwell, Ames, 143-165.
9. Stewart, D. M., Martin, A. W., 1970: Blood and fluid balance of the common tarantula Dugesiella hentzi. Z. Vergl. Physiologie, 70, 223-246.

10. Williams, D.L., 1992: Studies in arachnid disease. In Cooper, J. E., Pearce-Kelly, P., Williams, D. L., (Eds.): Arachnida: Proceedings of a One Day Symposium on Spiders and Their Allies. London, 1987. Keighley, UK, 116-125.

11. Wirkner, C.S., Huckstorf, K., 2013: Chapter 2: The circulatory system of spiders. Spider Ecophysiology, Springer-Verlag, Berlin 15-25.

12. Zachariah, T.T., Mitchell, M.A., Guichard, C.M., Singh, R.S., 2007: Haemolymph biochemistry ranges for wild caught Goliath Birdeater spiders (Theraphosa blondi) and Chilean Rose spiders (Grammostola rosea). Journal of Zoo and Wildlife Medicine, 38, 245-251.

Selected paper from the 59th STUDENT SCIENTIFIC CONFERENCE, Section I - Pre-clinical, held at the University of Veterinary Medicine and Pharmacy in Košice, SR, on April 6, 2016. 